CZASOPISMO INŻYNIERII LACDOWEJ, ŚRODOWISKA I ARCHITEKTURY JOURNAL OF CIVIL ENGINEERING, ENVIRONMENT AND ARCHITECTURE

\author{
JCEEA, t. XXXI, z. 61 (1/14), styczeń-marzec 2014, s. 333-342
}

\author{
Andrzej STUDZIŃSKI ${ }^{1}$ \\ Katarzyna PIETRUCHA-URBANIK ${ }^{2}$ \\ Wojciech KLUZ
}

\title{
ANALIZA STRAT WODY W SIECI WODOCIĄGOWEJ W STALOWEJ WOLI
}

\begin{abstract}
W publikacji przedstawiono analizę strat wody w sieci wodociagowej Stalowej Woli przeprowadzoną na podstawie danych uzyskanych z Miejskiego Zakładu Komunalnego Sp. z o. o. Stalowa Wola podczas eksploatacji sieci wodociagowej w latach 2008-2013, a także danych Głównego Urzędu Statystycznego. Oszacowane straty wody mają wartości niższe niż te odnotowane przez inne systemy zaopatrzenia $\mathrm{w}$ wodę. $\mathrm{W}$ pracy dokonano także charakterystyki podstawowych informacji o systemie zaopatrzenia w wodę w Stalowej Woli. Uzyskane wyniki odniesiono do danych innych systemów zaopatrzenia w wodę znajdujących się w województwie podkarpackim. Obliczenie jednostkowych wskaźników strat wody pozwoliło na uzyskanie szczegółowego obrazu sytuacji eksploatacyjnej wodociagu. Wszystkie jednostkowe wskaźniki objętościowe dotyczące strat wody wykazują tendencję malejącą w badanym okresie. Jednostkowy wskaźnik obciążenia hydraulicznego w odniesieniu do całej długości sieci wodociągowej w przeciagu ostatnich 5 lat wahał się w granicach od 37,73 do $42,33 \mathrm{~m}^{3} / \mathrm{km} \cdot \mathrm{d}$. Wskaźnik średniej wielkości strat $\mathrm{w}$ ciągu doby na jednego mieszkańca jest zbliżony do wartości odnotowanych w innych miastach w Polsce i zawiera się w przedziale od 5,99 do 11,96 $\mathrm{dm}^{3} / \mathrm{M} \cdot \mathrm{d}$. Korzystny jest także iloraz rzeczywistych strat rocznych oraz nieuniknionych strat rzeczywistych definiowany jako infrastrukturalny indeks wycieków, który wynosi od 1,6 do 3,3.
\end{abstract}

Słowa kluczowe: sieć wodociągowa, straty wody, wskaźniki strat wody

\section{Wprowadzenie}

Do końca lat 80. ubiegłego stulecia wielkości strat wody były monitorowane jedynie $\mathrm{z}$ powodu deficytu $\mathrm{w}$ zaopatrzeniu $\mathrm{w}$ wodę $\mathrm{w}$ niektórych miastach Polski. Ludność korzystająca z usług sieci wodociągowej nie była zainteresowa-

${ }^{1}$ Autor do korespondencji/corresponding author: Andrzej Studziński, Politechnika Rzeszowska, al. Powstańców Warszawy 6, 35-959 Rzeszów, tel. (17) 865 1703, e-mail: astud@ @rz.edu.pl

${ }^{2}$ Katarzyna Pietrucha-Urbanik, Politechnika Rzeszowska, al. Powstańców Warszawy 6, 35-959 Rzeszów, tel. (17) 8651703

${ }^{3}$ Wojciech Kluz, Politechnika Rzeszowska, al. Powstańców Warszawy 6, 35-959 Rzeszów, tel. (17) 8651703 
na oszczędzaniem wody ze względu na niską cenę wody. Awarie wodociagów u odbiorców wody nie były naprawiane, ponieważ koszt naprawy był wyższy niż koszt traconej wody. W wyniku zmian gospodarczych na początku lat 90 . cena wody znacząco wzrosła, powodując spadek objętości traconej wody [1-8]. Zmusiło to również przedsiębiorstwa wodociagowe do działań zmierzających do obniżania strat wody, co bezpośrednio przekładało się na wyniki finansowe przedsiębiorstwa.

Miasto jest obsługiwane przez wodociąg „Stalowa Wola”, którego głównym źródłem poboru wody są studnie ujęć „Krzyżowe Drogi” i „Stare Ujęcie”. Jest to sieć o geometrycznej strukturze mieszanej. Całkowita długość sieci wodociaggowej wzrosła z 83,3 km w 2000 r. do 194,4 km w 2013. Większość przewodów rozdzielczych jest wykonanych z materiałów PVC i PE o średnicach nominalnych 80,100,150, $200 \mathrm{~mm}$. Podłączenia większości użytkowników składają się z przewodów o średnicy DN $32 \mathrm{~mm}$. W tabeli 1. zestawiono dane dotyczące długości poszczególnych przewodów wodociagowych.

Tabela 1. Zestawienie długości sieci magistralnej i rozdzielczej dla lat 2008-2013

Table 1. Summary of the main and distribution length for the years 2008-2013

\begin{tabular}{|l|c|c|c|c|c|}
\hline \multicolumn{1}{|c|}{ Rodzaj danych } & $\mathbf{2 0 0 9}$ & $\mathbf{2 0 1 0}$ & $\mathbf{2 0 1 1}$ & $\mathbf{2 0 1 2}$ & $\mathbf{2 0 1 3}$ \\
\hline Długość sieci magistralnej $[\mathrm{km}]$ & 98,5 & 98,5 & 98,5 & 98,5 & 98,5 \\
\hline Długość sieci rozdzielczej $[\mathrm{km}]$ & 90,2 & 90,295 & 95,3 & 95,6 & 95,9 \\
\hline $\begin{array}{l}\text { Całkowita długość sieci wodocią- } \\
\text { gowej }[\mathrm{km}]\end{array}$ & 188,7 & 188,795 & 193,8 & 194,1 & 194,4 \\
\hline
\end{tabular}

Całkowita długość sieci magistralnej jest od 2009 r. niezmienna i wynosi $98,5 \mathrm{~km}$. W ciagu pięciu lat zmieniła się długość przewodów rozdzielczych z 90,2 do 95,9 km. Zwiększyła się także całkowita długość sieci wodociagowej o 5,7 km. W 2011 roku odnotowano największy jej przyrost, tj. 5,0 km. W 2009 roku podłączenia wodociągowe mierzyły $55,8 \mathrm{~km}$, w 2012 były zaś o $3,04 \mathrm{~km}$ dłuższe. Liczba przyłączy wodociaggowych $\mathrm{z}$ roku na rok zwiększała się, osiągając w 2011 r. wartość 2 599, tj. o 137 więcej niż w 2009 r. Jednocześnie odnotowano spadek liczby mieszkańców korzystających z wodociąuu. Obecnie ok. 98\% odbiorców ma dostęp do sieci zbiorowego zaopatrzenia w wodę.

Celem pracy jest analiza i ocena start wody w mieście Stalowa Wola w latach 2008-2013.

\section{Analiza strat wody}

Analiza strat wody w stalowowolskich wodociagach została przeprowadzona na podstawie danych uzyskanych od MZK Stalowa Wola w latach 2008-2013 oraz danych Głównego Urzędu Statystycznego [9]. W tabeli 2. zestawiono wartości strat wody w systemie wodociagowym. 
Tabela 2. Wartości strat w stalowowolskich wodociagach w latach 2008-2013

Table 2. The amount of losses in Stalowa Wola water supply for years 2008-2013

\begin{tabular}{|l|c|c|c|c|c|c|}
\hline \multicolumn{1}{|c|}{ Rodzaj danych } & $\mathbf{2 0 0 8}$ & $\mathbf{2 0 0 9}$ & $\mathbf{2 0 1 0}$ & $\mathbf{2 0 1 1}$ & $\mathbf{2 0 1 2}$ & $\mathbf{2 0 1 3}$ \\
\hline Objętość strat wody $\left[\mathrm{m}^{3}\right]$ & 187000 & 284000 & 207000 & 139000 & 177000 & 106000 \\
\hline $\begin{array}{l}\text { Dobowa objętość strat } \\
{\left[\mathrm{m}^{3} / \mathrm{d}\right]}\end{array}$ & 512,33 & 778,08 & 567,12 & 380,82 & 484,93 & 290,41 \\
\hline $\begin{array}{l}\text { Jednostkowa objętość } \\
\text { strat }\left[\mathrm{dm}^{3} / \mathrm{M} \cdot \mathrm{d}\right]\end{array}$ & 7,80 & 11,96 & 8,79 & 5,99 & 7,71 & 4,62 \\
\hline
\end{tabular}

Najwyższą wartość strat wody $778,08 \mathrm{~m}^{3} / \mathrm{d}$ odnotowano w $2009 \mathrm{r}$. Na jeden kilometr przewodów wodociagowych $\mathrm{w}$ czasie jednej doby średnio do gruntu wypłynęło $4,12 \mathrm{~m}^{3}$ wody. Średnia wielkość strat $\mathrm{w}$ ciagu doby na jednego mieszkańca mieściła się w przedziale 4,62-11,96 dm $3 \mathrm{dm}^{3} \mathrm{M} \cdot \mathrm{d}$. W 2013 roku straty wody wyniosły średnio $290,41 \mathrm{~m}^{3}$ na całej długości sieci w ciagu doby. Pomimo przyrostu długości sieci wodociagowej podczas badanego okresu odnotowano zmniejszenie objętości traconej wody. Na rysunku 1. przedstawiono średnie straty wody przypadające na jednostkę długości sieci w ciągu doby.

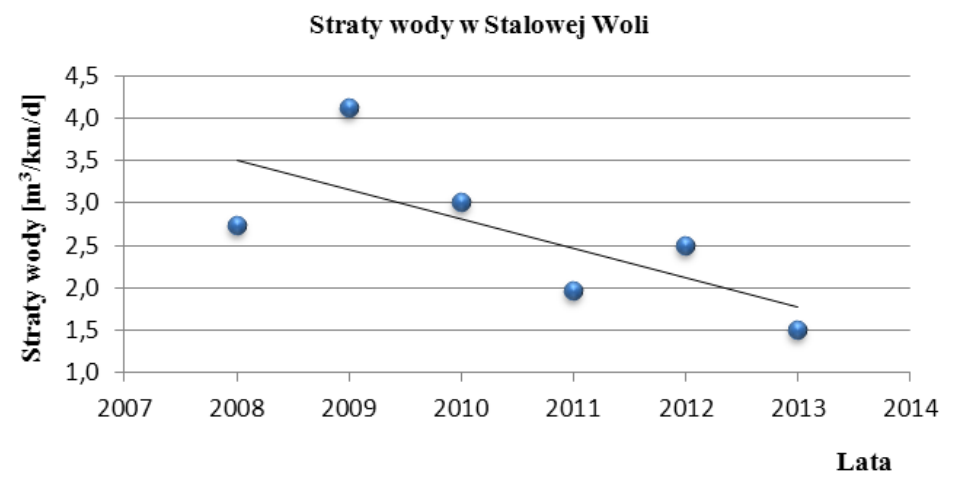

Rys. 1. Średnia objętość strat wody w Stalowej Woli

Fig. 1. The average volume of water losses in the Stalowa Wola

W latach 2008-2013 wartość średniej straty wody $x=2,635 \mathrm{~m}^{3} / \mathrm{km} / \mathrm{d}$, odchylenie standardowe zaś $\sigma=0,907$. Prosta regresji ma postać $y=-0,344 x+$ 695,1 . W tabeli 3. zestawiono wartości wskaźnika procentowego strat wody (PWS).

W latach 2009 i 2012 nastapił wzrost strat wody w porównaniu z rokiem ubiegłym. W 2013 roku zanotowano najniższy procentowy wskaźnik wody straconej 4,03\%. Wartość średnia wskaźnika PWS w badanych latach $x=6,59 \%$, odchylenie standardowe $\sigma=2,06 \%$. Prosta regresji jest opisana wzorem $y=$ $=-0,699 x+1412$. 
Tabela 3. Procentowy wskaźnik strat wody (PWS) dla lat 2008-2013

Table 3.The percentage of water loss (PWS) for the years 2008-2013

\begin{tabular}{|l|c|c|c|c|c|c|}
\hline \multicolumn{1}{|c|}{ Rodzaj danych } & $\mathbf{2 0 0 8}$ & $\mathbf{2 0 0 9}$ & $\mathbf{2 0 1 0}$ & $\mathbf{2 0 1 1}$ & $\mathbf{2 0 1 2}$ & $\mathbf{2 0 1 3}$ \\
\hline $\begin{array}{l}\text { Objętość wody wtłoczonej } \\
\text { do sieci }\left[\mathrm{m}^{3}\right]\end{array}$ & 2903524 & 2835885 & 2821383 & 2737199 & 2672834 & 2629267 \\
\hline Objętość strat wody $\left[\mathrm{m}^{3}\right]$ & 187000 & 284000 & 207000 & 139000 & 177000 & 106000 \\
\hline PWS [\%] & 6,44 & 10,01 & 7,34 & 5,08 & 6,62 & 4,03 \\
\hline
\end{tabular}

Na rysunku 2. przedstawiono procentowy wskaźnik strat wody porównywany z miastami Jasło oraz Tarnów. Najniższy wskaźnik strat wody we wszystkich badanych latach odnotowano w Stalowej Woli. Jasło posiadające porównywalną długość przewodów wodociągowych ma ponaddwukrotnie wyższy wskaźnik strat wody. Najwyższe wartości odnotowano również dla Tarnowa, jednak miasto to ma ponadtrzykrotnie dłuższą i co najistotniejsze najstarszą sieć wodociagowa. W Stalowej Woli od 2009 r. jest zauważalny spadek wartości analizowanego wskaźnika - jest to tendencja przeciwna do tej występującej w Tarnowie, gdzie następuje nieznaczny wzrost strat wody.

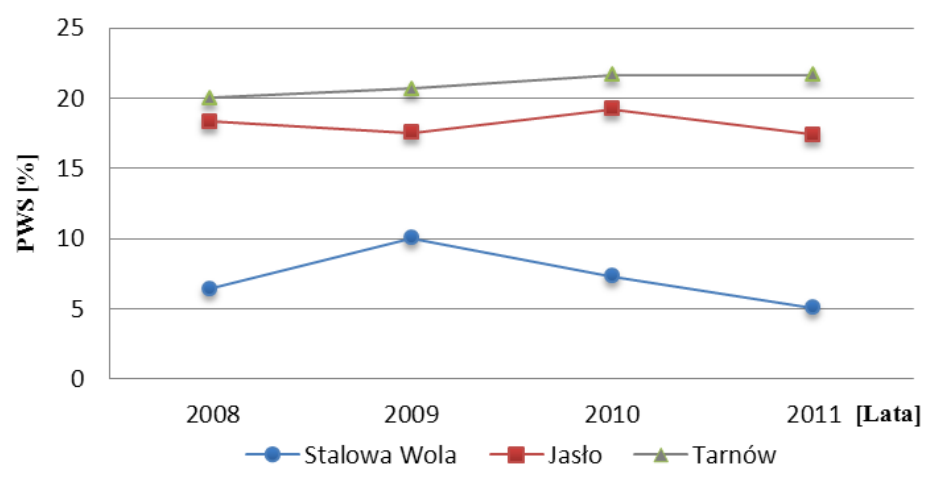

Rys. 2. Porównanie strat wody (PWS) w systemach zaopatrzenia w wodę miast Stalowa Wola, Jasło, Tarnów w latach 2008-2011

Fig. 2. Comparison of water loss (PWS) in the water supply of cities Stalowa Wola, Jasło, Tarnów in 2008-2011

W tabeli 4. zestawiono wartości wskaźnika jednostkowych strat rzeczywistych wody (RLB) wyznaczone w zależności od liczby przyłączy na $1 \mathrm{~km}$ sieci wodociagowej. Wskaźnik ten można wyznaczyć z następujących wzorów:

- jeśli liczba przyłączy $I_{p}<20$ przyłączy $/ \mathrm{km}$ sieci, to wskaźnik należy odnieść do długości sieci (bez przyłączy)

$$
R L B=\left(V_{s t r}\right) /\left(L_{c} \cdot 365\right)\left[\mathrm{m}^{3} / \mathrm{km} \cdot \mathrm{d}\right]
$$


- jeśli liczba przyłączy $I_{p} \geq 20$ przyłączy/km sieci, to wskaźnik oblicza się na jedno przyłącze

$$
R L B^{\prime}=\left(V_{s t r} \cdot 1000\right) /\left(I_{p} \cdot 365\right)\left[\mathrm{dm}^{3} / \mathrm{d} \cdot \text { przyłącze }\right]
$$

gdzie: $V_{s t r}-$ objętość strat wody [ $\mathrm{m}^{3} / \mathrm{rok}$,

$L_{c}$ - długość przewodów magistralnych i rozdzielczych [km],

$I_{p}-$ liczba przyłączy wodociągowych.

Tabela 4. Jednostkowe straty rzeczywiste wody odnotowane w latach 2008-2013

Table 4. Unit water losses for years 2008-2013

\begin{tabular}{|l|c|c|c|c|c|}
\hline \multicolumn{1}{|c|}{ Rodzaj danych } & $\mathbf{2 0 0 8}$ & $\mathbf{2 0 0 9}$ & $\mathbf{2 0 1 0}$ & $\mathbf{2 0 1 1}$ & $\mathbf{2 0 1 2}$ \\
\hline Liczba przyłączy wodociągowych & 2434 & 2462 & 2513 & 2559 & 2599 \\
\hline Straty wody $\left[\mathrm{m}^{3}\right]$ & 187000 & 284000 & 207000 & 139000 & 177000 \\
\hline $\begin{array}{l}\text { Jednostkowe straty rzeczywiste } \\
{\left[\mathrm{dm}^{3} / \mathrm{km}-\mathrm{d}\right]}\end{array}$ & 2,73 & 4,12 & 3,00 & 1,96 & 2,50 \\
\hline
\end{tabular}

Najwyższe średnie straty jednostkowe wystapiły w 2009 r., a najniższe w 2011. Wartość średnia wskaźnika $R B L$ za 5 lat wynosi $2,86 \mathrm{~m}^{3} / \mathrm{km} \cdot \mathrm{d}$. Odchylenie standardowe $\sigma=0,80 \mathrm{~m}^{3} / \mathrm{km} \cdot \mathrm{d}$. Na rysunku 3. przedstawiono straty nieuniknione wyznaczone jako suma trzech składowych, a są to przecieki nieuniknione w różnych rodzajach sieci wodociągowej. Przyjmuje się:

- $18 \mathrm{dm}^{3} / \mathrm{km} \cdot \mathrm{d} \cdot \mathrm{m}$ dla przewodów magistralnych i rozdzielczych bez przyłączy,

- $0,8 \mathrm{dm}^{3} / \mathrm{km} \cdot \mathrm{d} \cdot \mathrm{m}$ dla podłączeń wodociagowych do granicy działki,

- $25 \mathrm{dm}^{3} / \mathrm{km} \cdot \mathrm{d} \cdot \mathrm{m}$ dla liczby podłączeń wodociagowych od granicy działki do wodomierza.

Straty nieuniknione można wyznaczyć ze wzoru:

$$
U A R L=\left[18\left(L_{m}+L_{r}\right)+25 L_{p}+0,8 I_{p}\right] \cdot 0,365 \mathrm{p}\left[\mathrm{m}^{3} / \mathrm{rok}\right]
$$

gdzie: 0,365 - współczynnik przeliczeniowy na rok,

$L_{m}$-długość sieci magistralnej $[\mathrm{km}]$,

$L_{r}-$ długość sieci rozdzielczej $[\mathrm{km}]$,

$L_{p}-$ długość podłączeń wodociagowych $[\mathrm{km}]$,

$p$ - ciśnienie $\mathrm{w}$ danej strefie sieci wodociagowej $\left[\mathrm{mH}_{2} \mathrm{O}\right]$.

Wyznaczone straty nieuniknione mają zbliżoną wartość, nie odbiegając znacznie od siebie. Wartość średnia strat nieuniknionych $U A R L_{s r}=86972,01 \mathrm{~m}^{3}$. W 2009 roku wskaźnik objętości wody niedochodowej osiagnął wartość $10,01 \%$, co świadczy o dużej różnicy straconej wody w porównaniu z innymi latami. Najniższą wartość wskaźnika NWR odnotowano w 2008 r., tj. 3,22\%. 
Odchylenie standardowe dla lat 2008-2012 wynosi $\sigma=2,69 \%$. Prostą regresji opisano wzorem $y=-0,255 x+518,5$.

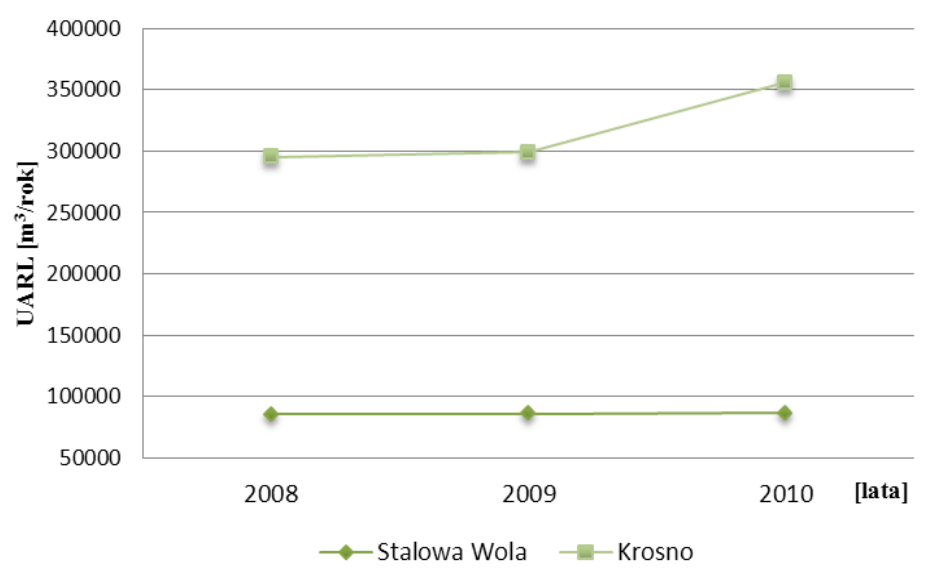

Rys. 3. Zestawienie wskaźnika UARL dla Stalowej Woli i Krosna w latach 2008-2011

Fig. 3. Comparison of UARL indicator for Stalowa Wola and Krosno in $2008-2011$

Z porównania wartości wskaźnika strat nieuniknionych dla lat 2008-2010 w przypadku miast Stalowej Woli i Krosna (rys. 3.) wynika, że w Krośnie straty nieuniknione w 2008 r. były 3,5-krotnie wyższe, a w 2010 wyniosły $410 \%$ wartości wskaźnika odnotowanego dla Stalowej Woli. Jest to związane z ponaddwukrotnie dłuższą siecią wodociagową w Krośnie oraz gorszym stanem technicznym przewodów.

Istotnym parametrem w określaniu strat wody w systemach wodociagowych jest obciążenie hydrauliczne sieci, które przedstawia średnią objętość wody wtłaczanej do sieci przez dobę. Aby możliwe było poprawne wykonanie analizy porównawczej, a co za tym idzie otrzymanie poprawnych wyników, oprócz strat należy ująć także obciążenia hydrauliczne systemów wodociagowych. Wskaźnik ten można wyznaczyć ze wzoru:

$$
Q o s=\frac{V_{d s}}{365 L_{c}}\left[\mathrm{~m}^{3} / \mathrm{d} \cdot \mathrm{km}\right]
$$

gdzie: $V_{d s}$ - objętość wody wtłaczanej do sieci $\left[\mathrm{m}^{3}\right]$,

$L_{c}$ - całkowita długość sieci wodociagowej $[\mathrm{km}]$.

Na rysunku 4. porównano obciążenia hydrauliczne sieci dla miast: Tarnowa, Jasła, Stalowej Woli. Najniższe obciążenie hydrauliczne sieci odnotowano w Jaśle ze względu na mniejszą liczbę odbiorców. Najwyższe obciążenie wystę- 
puje w przewodach wodociagu miasta Tarnowa. Jak wynika z porównania, ważnym czynnikiem w analizie obciążenia jest liczba odbiorców wody. Im większa liczba odbiorców, tym większe obciążenie hydrauliczne sieci. Przy większym obciążeniu sieci wyższe jest prawdopodobieństwo wystąpienia awarii, a co za tym idzie strat wody.

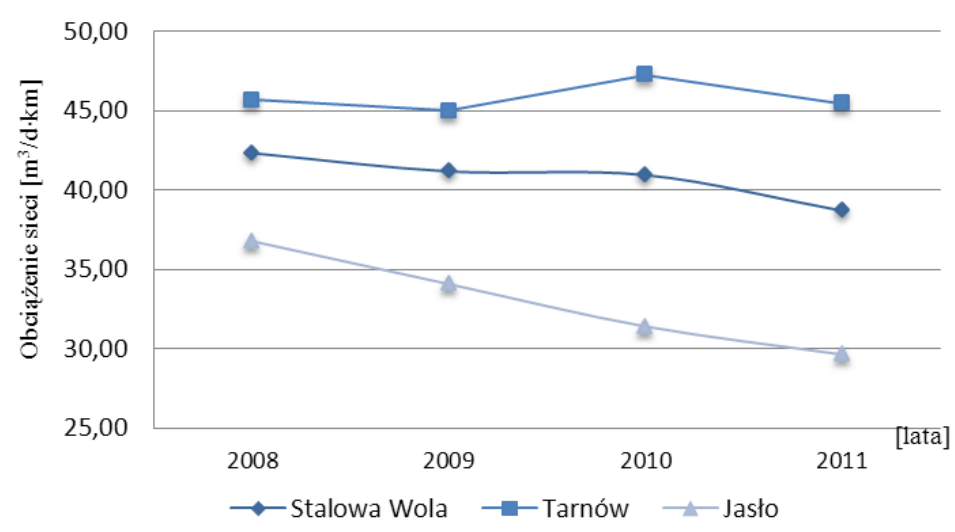

Rys. 4. Zestawienie obciążenia hydraulicznego sieci dla Tarnowa, Jasła i Stalowej Woli w latach 2008-2011

Fig. 4. Comparisonof hydraulic load network for Tarnów, Jasło and Stalowa Wola in 2008-2011

Na rysunku 5. zilustrowano straty jednostkowe oraz obciążenie hydrauliczne sieci w latach 2008-2012. Z przedstawionych danych wynika, że w przypadku miasta o małym obciążeniu hydraulicznym sieci (np. Stalowa Wola, gdzie obciążenie hydrauliczne mieści się w przedziale $37,00-43,00 \mathrm{~m}^{3} / \mathrm{d} \cdot \mathrm{km}$ ) występują jednostkowe straty rzeczywiste o wartości $1,96-4,12 \mathrm{~m}^{3} / \mathrm{km} \cdot \mathrm{d}$.

Na podstawie infrastrukturalnego indeksu wycieków według IWA zamieszczonego w tab. 5. można ocenić stan przewodów wodociągowych. Wskaźnik ten wyznacza się za pomocą ilorazu rzeczywistych strat rocznych oraz nieuniknionych strat rzeczywistych:

$$
I L I=\frac{V_{s t r}}{U A R L}[-]
$$

gdzie: $V_{s t r}$ - objętość rzeczywistych strat wody $\left[\mathrm{m}^{3} / \mathrm{rok}\right]$,

$U A R L$ - objętość nieuniknionych rzeczywistych strat $\left[\mathrm{m}^{3} / \mathrm{rok}\right]$. 


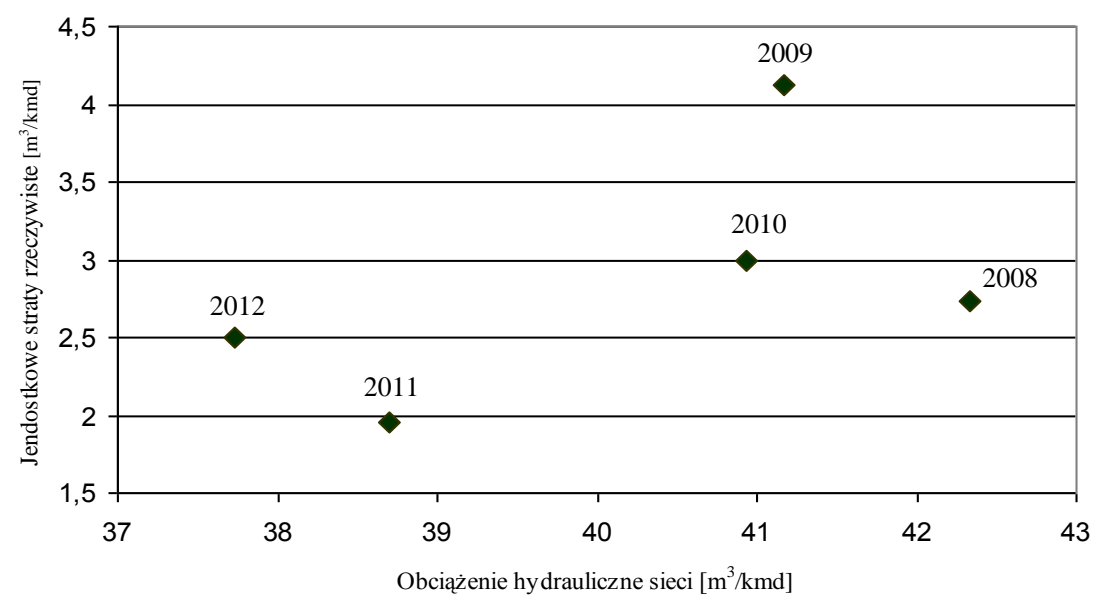

Rys. 5. Jednostkowe straty wody ze zmiennym obciążeniem wody w przewodach wodociagowych Stalowej Woli odnotowane w latach 2008-2011

Fig. 5. Unit water loss from the variable load of water in water pipes in Stalowa Wola in 2008-2011

Tabela 5. Infrastrukturalny indeks wycieków odnotowany w Stalowej Woli

Table 5. Infrastructure Leakage Index in Stalowa Wola

\begin{tabular}{|c|c|c|c|c|c|}
\hline Rodzaj danych & $\mathbf{2 0 0 8}$ & $\mathbf{2 0 0 9}$ & $\mathbf{2 0 1 0}$ & $\mathbf{2 0 1 1}$ & $\mathbf{2 0 1 2}$ \\
\hline ILI wg IWA & 2,18 & 3,29 & 2,39 & 1,58 & 2,00 \\
\hline Stan sieci wodociągowej & dobry & słaby & dobry & dobry & dobry \\
\hline
\end{tabular}

Stratami nieuniknionymi określa się straty, których nie można usunąć z sieci wodociagowej, ponieważ nie jest to wskazane ze względów ekonomicznych. Stosując wskaźnik ILI, można ocenić stan techniczny sieci wodociagowej. W zależności od wyznaczonej wartości ILI można wyróżnić różne rodzaje stanu technicznego sieci wodociagowej, co zostało przedstawione w opracowaniach $[8,10,11]$. Najniższą wartość wskaźnika indeksu wycieku odnotowano w 2011 r. W latach 2008 i 2010-2012 przewody wodociagowe oceniono na stan dobry, najgorszy ich stan odnotowano zaś w 2009 r.

\section{Wnioski}

Analiza strat wody w przewodach wodociagowych w Stalowej Woli pozwoliła na sformułowanie następujących wniosków:

1. Objętość wody wtłoczonej do sieci zmierzona w 2013 r. o wartości 2629 tys. $\mathrm{m}^{3}$ jest mniejsza o $9,44 \%$ w porównaniu $\mathrm{z}$ wartością odnotowaną w 2008 r. Odnotowano również spadek objętości wody sprzedanej ogółem oraz wody przeznaczonej na cele technologiczne wodociagu. 
2. Wartość średnia strat wody z lat $2008 \div 2013$ wynosi $2,635 \mathrm{~m}^{3} / \mathrm{km} \cdot \mathrm{d}$, odchylenie standardowe $\sigma=0,907$. Tendencję malejącą opisano równaniem $V_{\text {str }}=$ $-0,344 x+695,14$.

3. W 2013 roku zanotowano najniższy procentowy wskaźnik wody straconej (PWS) o wartości 4,03\%. Wartość średnia wskaźnika PWS w badanych latach wyniosła 6,59\%, odchylenie standardowe zaś $\sigma=2,06 \%$.

4. W 2009 roku wskaźnik objętości wody niedochodowej osiągnął najwyższą wartość 10,01\%. Najniższą wartość wskaźnika NWR zanotowano w 2008 r., tj. $3,22 \%$.

5. Istotnym czynnikiem w określaniu strat wody w systemach wodociagowych jest obciążenie hydrauliczne sieci. Średnie obciążenie hydrauliczne sieci wynosi $40,17 \mathrm{~m}^{3} / \mathrm{d} \cdot \mathrm{km}$. Najniższą wartość tego czynnika odnotowano w $2012 \mathrm{r}$., tj. $37,73 \mathrm{~m}^{3} / \mathrm{d} \cdot \mathrm{km}$, najwyższą zaś w $2008, \mathrm{tj} .42,33 \mathrm{~m}^{3} / \mathrm{d} \cdot \mathrm{km}$.

6. Porównując wielkości procentowe strat wody odnotowane w $2011 \mathrm{r}$. w analizowanych miastach, stwierdzono najniższy wskaźnik w Stalowej Woli, jest on bowiem niższy o $12,31 \%$ od Jasła i o $16,59 \%$ od Tarnowa.

7. Wyznaczony infrastrukturalny indeks wycieków (ILI) waha się od wartości 1,58 (2011 r.) do 3,29 (2009 r.). Stan techniczny stalowowolskich wodociągów według IWA oraz AWWA można określić jako dobry.

W celu stałego zmniejszania objętości strat wody konieczne jest prowadzenie ciagłego monitoringu sieci wodociagowej w mieście Stalowa Wola oraz działań mających za zadanie zmniejszenie traconej wody.

\section{Literatura}

[1] Dohnalik P.: Straty wody w miejskich sieciach wodociagowych. Wydaw. Polskiej Fundacji Ochrony Zasobów Wodnych, Bydgoszcz 2000.

[2] Kluz W.: Analiza strat wody w miejscowości Stalowa Wola. Politechnika Rzeszowska, Rzeszów 2014 (praca niepublikowana).

[3] Mayer P. et al.: AWWA Leak Detection \& Water Accountability Comittee Report. Residential End Uses of Water. AWWA Research Foundation, 1999.

[4] Pietrucha-Urbanik K., Studziński A.: Analiza strat wody wodociagu krośnieńskiego. Gaz, Woda i Technika Sanitarna, nr 10, 2012, s. 452-454.

[5] Rak J.: Awaryjność sieci wodociągowych w miastach polskich. Wodociagi Polskie, z. 3, nr 27, 2003, s. 11-14.

[6] Rak J.R., Tunia A.: Analiza i ocena strat wody w wodociagu Rzeszowa. Instal, Teoria i Praktyka w Instalacjach, nr 5, 2012, s. 42-45.

[7] Speruda S., Radecki R.: Ekonomiczny poziom wycieków. Wydaw. Translator s.c., Warszawa 2003.

[8] World Bank Institute Performance. NRW Training Module 6. Performance Indicators, 2005.

[9] MZK Stalowa Wola. Dane eksploatacyjne za okres 2008-2013.

[10] Hirner W., Lambert A.: Losses from Water Supply Systems: Standard terminology and recommended performance measures. IWA, London 2000. 
[11] Koral W.: Metodyka obniżania poziomu przecieków w sieciach wodociągowych. Wodociągi - Kanalizacja, nr 6, 28, 2006, s. 26-29.

\title{
ANALYSIS OF WATER LOSS IN STALOWA WOLA
}

\author{
S u m m a r y
}

In the article the analysis of water losses of the Stalowa Wola water network has been presented made on the basis of data obtained from the Municipal Department Sp. z oo Stalowa Wola during the networkoperation of water supply system in the period 2008-2013, as well as the data from the Central Statistical Office. Estimated water losses indicators have better values than the other water supply systems. The work also includes basic information about the characteristics of the water supply system in Stalowa Wola. The results regarded other water supply systems located in Podkarpackie province. An analysis of the distributional (up to $6.2 \mathrm{~km}$ ) and water supply connections lengths (an increase of $58.9 \mathrm{~km}$ ) indicates that the water network of Stalowa Wola is constantly expanded. The calculation of unit rates of water loss allowed to obtain a detailed picture of the operational situation of the operational water supply. All unit volume indicators on water losses show a downward trend in the considered period. Unit hydraulic loading rate for the entire length of the water supply network-provided for the past 5 years ranges from 37.73 to 42.33 $\mathrm{m}^{3} / \mathrm{km} \cdot \mathrm{d}$.Index of the average size of losses per day per capita is similar to other cities in Poland ranges from 5.99 to $11.96 \mathrm{dm}^{3} / \mathrm{M} \cdot \mathrm{d}$. The quotient of the actual losses and unavoidable annual real losses defined as infrastructure leakage index is preferred and ranges from 1.6 to 3.3.

Keywords: water network, water losses, the water losses indicators

Przestano do redakcji:20.04.2014 $r$.

Przyjęto do druku: 02.06.2014 r.

DOI: $10.7862 /$ rb.2014.23 